\title{
Patterns of pollen dispersal and mating in a population of the clonal plant Sagittaria latifolia
}

\author{
Samantha Stephens $^{1} \quad$ Mark van Kleunen $^{2,3}$ (D) Marcel E. Dorken ${ }^{1,4}$ (D)
}

${ }^{1}$ Environmental and Life Sciences Graduate Program, Trent University, Peterborough, ON, Canada

${ }^{2}$ Ecology, Department of Biology, University of Konstanz, Konstanz, Germany

${ }^{3}$ Zhejiang Provincial Key Laboratory of Plant Evolutionary Ecology and Conservation, Taizhou University, Taizhou, China

${ }^{4}$ Department of Biology, Trent University, Peterborough, ON, Canada

\section{Correspondence}

Marcel E. Dorken

Email: marceldorken@trentu.ca

\section{Funding information}

Natural Sciences and Engineering Research Council of Canada; Humboldt Research Fellowship

\begin{abstract}
1. Increased plant size is generally expected to have negative consequences for mating by increasing pollen transfer between flowers of the same plant. Such geitonogamous self-pollination would then reduce sexual fitness through both female and male function. However, recent theoretical work has indicated that when plants grow clonally, the outward expansion of plants caused by clonal growth might have positive effects on siring without substantially increasing rates of self-pollination.

2. We investigated patterns of pollen dispersal, selfing and siring in a monoecious population of the clonal plant Sagittaria latifolia, in which clones varied in size and the extent of intermingling with other clones. A spatially explicit statistical model based on the inferred pollen dispersal kernel was constructed to examine the mechanisms underlying observed mating patterns.

3. Pollen dispersal typically occurred over distances that exceeded the spatial extent of clones. There was a positive association between clone size (measured as the number of ramets per genet) and the likelihood that clones were intermingled with the shoots of other clones. Together, these patterns of pollen dispersal and clonal intermingling resulted in a weak positive association between clone size and selfing rates and a strong positive association between clone size and outcross siring success. These patterns were replicated in the spatially explicit model, indicating that the intermingling of clones is an important determinant of mating patterns in this population.
\end{abstract}

4. Synthesis. Our study provides the first examination of the pollen dispersal kernel for a clonal plant. It is the first study providing empirical support for model predictions that potentially negative effects of increased selfing in large clones might be offset by increased siring success. This implies that the negative consequences of becoming large do not necessarily apply to clonal plants.

\section{KEYWORDS}

clonal growth, dispersal kernel, geitonogamy, MLTR, monoecy, plant mating, plant reproductive ecology, Sagittaria latifolia (broadleaf arrowhead)

\section{INTRODUCTION}

Sexual reproduction in immobile organisms is constrained by their inability to actively seek out mating partners. For these organisms, mating is often enacted by third-party vectors that move gametes between neighbouring individuals. Moreover, because sessile organisms are often hermaphroditic and have a modular construction, mating among neighbouring modules can result in varying degrees of impairment to sexual fitness through female function (e.g. the clogging of female receptive tissues by pollen from other modules of 
the same individual, self-pollination and self-fertilization, inbreeding depression; reviewed in Barrett, 2002) and male function (e.g. reductions to siring success via pollen discounting; Harder \& Barrett, 1995). These challenges to mating are widely recognized for flowering plants, for which large size and the concomitant increase in the number of modules per individual have been shown to be associated with increased self-pollination and reduced siring success (e.g. Karron \& Mitchell, 2012).

These challenges to mating might be particularly acute for clonal plants, for which there are few constraints on overall plant size. An early study showed that clones (genets) with more shoots (ramets) should have higher rates of self-pollination (Handel, 1985). Since then, the prevailing view has been that clonal growth has negative consequences for mating (Charpentier, 2002; Vallejo-Marín, Dorken, \& Barrett, 2010). However, more recent empirical studies have not found an association between clone size and selfing rates (Liao et al., 2009; Matsuo et al., 2014). Moreover, a theoretical study and an experiment involving artificial flowers have shown that increases in genet size should not necessarily lead to higher rates of self-pollination and might even promote outcross siring success (Liao \& Harder, 2014; Van Drunen, van Kleunen, \& Dorken, 2015). These two studies made the simplifying assumption that all plants have equal reproductive effort regardless of the number of ramets per genet. However, in natural populations, variation in age and resource acquisition among genets will result in variation in pollen and ovule production. This joint variation in genet size and reproductive investment could have strong effects on realized patterns of mating.

Previous studies of mating patterns in populations of clonal plants have indicated that the spatial arrangement of genets can have pronounced effects on the magnitude of selfing (Albert, Raspé, \& Jacquemart, 2008; Liao \& Harder, 2014; Somme, Mayer, Raspé, \& Jacquemart, 2014 and see Reusch, 2001; Vandepitte, De Meyer, Jacquemyn, Roldan-Ruiz, \& Honnay, 2013). Indeed, the earlier study by Handel (1985), indicating that clonality can interfere with mating by increasing geitonogamous pollination (i.e. the movement of pollen between flowers of a plant, or for clonal plants, a genet), involved plants with little to no intermingling of ramets of different genets. Selfing in clonal plants can involve a high degree of geitonogamous pollination (Eckert, 2000), and this form of selfing is expected to reduce opportunities to sire seeds on other genets because of pollen discounting (Harder \& Barrett, 1995). As a result, clonal clustering and the associated high degree of selfing might be expected to result in a nonlinear, decelerating association between total male reproductive investment and siring success (Van Drunen et al., 2015). Indeed, a previous study of a rhizomatous, dwarf bamboo provided evidence that clonal expansion might result in nonlinear, decelerating associations between clone size and siring success (Matsuo et al., 2014), but whether this should be a general feature of clonal plants remains unclear. Theoretical analysis of mating patterns in clonal populations indicates that so long as clones are not tightly clustered, these negative consequences for mating should be offset by increased effective pollen dispersal distances (Van Drunen et al., 2015). In particular, the subdivision of reproductive effort across ramets within clones is expected to increase pollen carry-over, linearizing the association between male investment and siring success (Dorken \& Van Drunen, 2010 and see Wilson, Thomson, Stanton, \& Rigney, 1994).

Here we test the hypothesis that clonal expansion can benefit mating success by increasing intermingling among clones (Van Drunen et al., 2015) and the subdivision of reproductive effort among ramets (Dorken \& Van Drunen, 2010). In particular, we test the predictions that: (a) clonal expansion enables greater outcross siring success by increasing the number of mating partners that occur within typical pollen dispersal distances; (b) this increase in siring success occurs with minimal costs to mating arising from geitonogamous selfing. If large clones have greater siring success than smaller clones and have low rates of selfing, we further expect that (c) there will be a linear association between genet-level investment in male function and siring success. To test these predictions, we mapped all flowering ramets $(n=506)$ in an isolated population of the monoecious clonal aquatic plant Sagittaria latifolia and tracked their flowering phenology over one season. Sagittaria latifolia is a monoecious clonal plant, and clones have the potential to be highly intermingled (Dorken \& Barrett, 2003). We genotyped these ramets using simple sequence repeat (SSR) loci and, from a sample of seeds from each plant, estimated selfing rates and identified sires. The observed siring events were used to fit a pollen dispersal kernel. To evaluate our understanding of the processes driving the observed mating patterns in this population, we modelled the mating patterns expected under the inferred pollen dispersal kernel. In particular, we reconstructed the observed mating patterns from the inferred pollen dispersal kernel and the spatial and phenological data collected in the population.

\section{MATERIALS AND METHODS}

\subsection{Study system}

Sagittaria latifolia Willd. is a widespread emergent clonal aquatic plant common to wetland habitats throughout eastern North America and naturalized in Europe (van Kleunen et al., 2019). Populations are common in the regions surrounding the Great Lakes in eastern North America where both monoecious (hermaphroditic plants with unisexual flowers) and dioecious (unisexual plants) populations occur, often in close geographic proximity (Dorken \& Barrett, 2004a). Plants are self-compatible, and there are no compatibility barriers between plants from the two sexual system (Dorken \& Barrett, 2004 b). It produces stolons that average approximately $30 \mathrm{~cm}$ in length (Dorken \& Barrett, 2003); clonal growth therefore leads to the outward expansion of the genet by relatively large increments. Moreover, stolons disintegrate at the end of each growing season and the perennating structures (corms) can float. Clones in populations of $S$. latifolia could be highly intermingled, although patterns of spatial autocorrelation indicate that clones are aggregated and only moderately intermingled (Yakimowski \& Barrett, 2014). 
Because we were interested in the effects of clonality on patterns of selfing, and selfing is not possible in dioecious populations, we chose an isolated monoecious population for this study. In monoecious populations, flowering ramets produce synchronously protogynous inflorescences. Flowers open for one day, and female flowers, which occupy the basal whorls of the inflorescence, open first. Once the female phase is over (usually all female flowers in an inflorescence open on the same day) a more protracted male phase begins, with typically two to three male flowers opening per day (Perry \& Dorken, 2011). Because the female and male sex phases of inflorescences do not usually overlap, when selfing occurs it will involve inter-ramet geitonogamy (Dorken, Friedman, \& Barrett, 2002). Clonal growth in S. latifolia occurs via the production of vegetative ramets during the growing season and corms during and after flowering at the terminal end of axillary stolons. Flowers have an open architecture, and pollen and nectar are available to a broad range of insect pollinators, including bumblebees, solitary bees, skippers and hover flies, all of which have been observed to visit S. Iatifolia in the region where the study was conducted. In the population studied here, hover flies and solitary bees were the most commonly observed floral visitors.

\subsection{Sampling and SSR genotyping}

The site we chose for this study occurred in a shallow area of Thompson Creek in Meadowvale Park, Peterborough, Ontario. Flowering ramets were patchily distributed over an area of approximately $25 \mathrm{~m} \times 60 \mathrm{~m}$ and isolated from other populations of S. latifolia by at least $100 \mathrm{~m}$. Between June and September 2013, we visited the site daily to record the number and sex of flowers produced on each flowering ramet. All flowering ramets were tagged and a sample of leaf tissue from the youngest leaf per ramet was taken for subsequent DNA extraction, yielding a total sample of 506 ramets. After flowering had finished, all ramets were mapped using triangulation (e.g. Ahee, Van Drunen, \& Dorken, 2015).

Collected leaf tissue was dried using silica and stored at $-20^{\circ} \mathrm{C}$ for genetic analysis. At the end of the season, we collected seeds from all ramets with mature fruits. For these ramets, we collected all fruits, dried them in coin envelopes at room temperature and then stored them at $4^{\circ} \mathrm{C}$. During fruit maturation the population was monitored at least twice per week and fruits were collected as they matured. A total of 757 fruits were collected from 220 ramets, with an average of 2.7 fruits collected per ramet. We aimed to sample one seed per fruit for paternity analysis and selfing-rate estimation; however, not all fruits matured and viable DNA was obtained from 358 seeds representing 154 ramets. Air-dried seeds were soaked in deionized water at $4^{\circ} \mathrm{C}$ for a minimum of 1 day to loosen the seed from the achene and increase effectiveness of grinding. Maternal tissues (including the achene and seed coat) were removed using needle-tipped forceps. Seeds were then crushed using standard forceps. DNA extraction was performed using QuickExtract ${ }^{\mathrm{TM}}$ Seed DNA Extraction Solution (Epicenter) following the manufacturer's protocol. DNA amplification and genotyping were carried out using the procedure described above for leaf tissue.

DNA amplification and SSR genotyping followed the methods outlined in Yakimowski, Rymer, Stone, Barrett, and Dorken (2009). Dried leaf tissue was ground into a powder using a MM 300 Retsch mixer mill (Haan, Germany). DNA was then extracted using E.Z.N.A. ${ }^{\circledR}$ Plant DNA Mini Kit (Omega Bio-Tek., Inc.) following the manufacturer's protocol for dried specimens. Extracted DNA concentrations were measured using fluorometric quantitation and each sample was then diluted to approximately $50 \mathrm{ng} / \mu \mathrm{l}$. Four nuclear SSR microsatellite loci (SL65, SL06, SL75 and SL27) were amplified individually, and five loci (SL30, SL88, SL21, SL09, SL74) were amplified in two multiplexes using fluorescently tagged primers. For individual reactions, the PCR master mix contained $0.2 \mu \mathrm{M}$ of forward and reverse primers, $0.15 \mathrm{mM}$ dNTPs, $1 X$ buffer, $2 \mathrm{mM} \mathrm{MgCl}$, $0.3 \mathrm{mM}$ BSA and $0.05 \mathrm{U} / \mathrm{rxn}$ Taq DNA polymerase (Invitrogen ${ }^{\mathrm{TM}}$ ) in a final volume of $10 \mu \mathrm{l}$. DNA amplification was conducted using Eppendorf Mastercycler ${ }^{\circledR}$ thermal cyclers (Eppendorf). Cycle conditions were as follows: denaturing at $94^{\circ} \mathrm{C}$ for $3 \mathrm{~min}$, amplification repeated for $30 \mathrm{cycles}$ of $94^{\circ} \mathrm{C}$ for $30 \mathrm{~s}$, annealing at $60-62^{\circ} \mathrm{C}$ for $30 \mathrm{~s}$ and $72^{\circ} \mathrm{C}$ for $45 \mathrm{~s}$, with a final elongation at $72^{\circ} \mathrm{C}$ for $45 \mathrm{~min}$. All primers had an annealing temperature of $60^{\circ} \mathrm{C}$, except for SL65, which was annealed at $62^{\circ} \mathrm{C}$. Multiplex 1 contained SL21 forward and reverse primers at concentrations of $0.1 \mu \mathrm{M}$ and SL30 had primer concentrations of $0.19 \mu \mathrm{M}$; the rest of the reaction mixture contained $0.15 \mathrm{mM}$ dNTPs, $1 \mathrm{X}$ buffer, $1.3 \mathrm{mM} \mathrm{MgCl}, 0.3 \mathrm{mM}$ BSA and $0.5 \mathrm{U} / \mathrm{rxn}$ GoTaq Flexi DNA polymerase (Promega). Multiplex 2 contained SL88 forward and reverse primers at concentrations of $0.18 \mu \mathrm{M}$, SL09 primers at concentrations of $0.1 \mu \mathrm{M}$ and SL74 primer concentrations of $0.16 \mu \mathrm{M}$ with the remaining reaction mixture containing $0.15 \mathrm{mM}$ dNTPs, $1 \mathrm{X}$ buffer, $1.6 \mathrm{mM} \mathrm{MgCl}, 0.3 \mathrm{mM} \mathrm{BSA}$ and $0.5 \mathrm{U} / \mathrm{rxn}$ GoTaq Flexi DNA polymerase (Promega). Amplification for multiplexes involved initial denaturation at $94^{\circ} \mathrm{C}$ for $3 \mathrm{~min}, 25$ cycles of $94^{\circ} \mathrm{C}$ for $45 \mathrm{~s}$, annealing at $57^{\circ} \mathrm{C}$ for multiplex 1 and $56.5^{\circ} \mathrm{C}$ for multiplex 2 for $45 \mathrm{~s}$ and $72^{\circ} \mathrm{C}$ for $45 \mathrm{~s}$, and a final elongation at $72^{\circ} \mathrm{C}$ for $10 \mathrm{~min}$. The quality of amplification products was evaluated on an agarose gel and then diluted $20 \times$ using $\mathrm{ddH}_{2} \mathrm{O}$. Then $0.7 \mu \mathrm{l}$ of this dilution was mixed with $9 \mu \mathrm{l}$ of HiDi containing ROX 500 size standard (Applied Biosystems) and run on an ABI3730 (Applied Biosystems). Loci SL09 and SL30 appeared to have a high frequency of null alleles and these loci were not included in the analyses presented below. Genotypes were scored using Genemarker ${ }^{\circledR}$ software (v 1.6; Softgenetics ${ }^{\circledR}$ ).

We identified 210 unique multilocus genotypes (MLGs). The probability that ramets sharing the same MLG arose from independent instances of sexual reproduction was calculated using the psex_Fis function in the RCLONE package (v. 1.0.2.; Bailleul, Stoeckel, \& ArnaudHaond, 2016) of R (v. 3.4.4.; R Core Team, 2018). All but one of the calculated values of $P_{\text {sex }}$ was below 0.03 . Accordingly, ramets with identical MLG assignments were assumed to have been the product of clonal growth. To account for scoring errors and somatic mutations, MLGs that differed by one allele at any locus were assigned to the same multilocus lineage (MLL; Schnittler \& Eusemann, 2010) using the 
MLL_generator function from the RCLONE package and resulting in 169 unique MLLs.

\subsection{Paternity and inter-ramet mating distances}

Paternity was inferred for seeds using the likelihood approaches implemented in CERVUS (v 3.0.7; Kalinowski, Taper, \& Marshall, 2007; Marshall, Slate, Kruuk, \& Pemberton, 1998) and COLONY2 (v. 2.0.6.5; Jones \& Wang, 2010; Wang, 2004, 2018). Our sampling of potential sires in this isolated population was likely to have been nearly complete, and results from both CERVUS and COLONY2 were qualitatively similar. Below we report results involving paternity assignments from COLONY2. Both programs allow for errors in genotyping; for our COLONY2 run, we set per locus stochastic error rates from the output provided by a previous run of CERVUS. Calculations were made using the full likelihood (FL) option; according to the authors of COLONY2, this option provides the greatest accuracy in parentage assignments. Paternity analysis was conducted using MLG assignments to account for the possibility of somatic mutations within MLGs; these mutations could be passed on to offspring and could reduce assignment probabilities for MLLs comprised of ramets with different alleles at any one of the SSR loci used here. The resulting data were analysed at the MLL level to enable clone-level calculations of siring success. For the corresponding dataset, which contains information on all options used for the COLONY2 parentage analysis, please see the R script in the associated digital repository (https://doi.org/10.5061/dryad.qz612jmb8; Stephens, van Kleunen, \& Dorken, 2020).

We calculated inter-ramet mating distances and used these values to infer the underlying pollen dispersal kernel using maximum likelihood. To do this, we largely followed the procedure outlined by Hardy et al. (2004) using a one-parameter dispersal kernel (the exponential decay function) and bootstrapping ramets from MLGs identified as the sire of a particular seed to obtain ramet locations and male flower production (two-parameter dispersal kernels, including the exponential-power function used by Hardy et al., 2004 failed to converge). Only sires assigned with greater than $95 \%$ probability were retained for the analysis of pollen dispersal distances. For other analyses, the assignment probability for the most probable sire was used to weight the number of inferred siring events per MLL. However, including seeds that were assigned to sires with less than $95 \%$ probability in our calculations of pollen dispersal distances provided results that were qualitatively similar to those reported below. Including or excluding these seeds also yielded qualitatively similar results for analyses of clonal intermingling and siring patterns. The bootstrapping procedure resulted in a rough likelihood surface rendering standard optimization algorithms (e.g. derivative-based methods) unsuitable for identifying the maximum likelihood estimate. As a result, direct-search was used to estimate the maximum likelihood parameter value for the negative exponential distribution (Bolker, 2008). For details and the corresponding R scripts used for the bootstrapping procedure and the maximum likelihood calculations see Supporting Information: Methods S1.

\subsection{Genet size and intermingling}

Our aim in quantifying patterns of clonal intermingling and the spatial clustering of genets was to characterize spatial relations in terms of their implications for mating patterns. Accordingly, ramets were defined as being intermingled with other genets if they were likely to disperse pollen to (or receive pollen from) other genets and clustered if they were likely to disperse pollen to other ramets from the same genet. Specifically, patterns of intermingling were quantified as the number of ramets from other genets (MLLs) versus the same genet (clustering) that occurred within the first 10th, 25th and 50th percentiles of the (bootstrapped) distribution of inter-ramet mating distances (as described above). These distances are referred to below as the short, intermediate and typical inter-ramet mating distances (SIRMD, iIRMD and tIRMD respectively). These counts of pairwise inter-ramet distances were then summed across ramets within a genet. Note that this method could result in the repeated counting of the same ramet (as many times as the ramet occurred within this minimum distance for each ramet per genet). This was done to account for the fact that the probability of overlap in sex phases between ramets increases with the number of ramets in local mating neighbourhoods of Sagittaria (Wang et al., 2012). Because these distances were used to scale the area spanned by a genet, in the Section 3 below we refer to these distances in terms of patterns of occupancy-genets were assumed to span smaller versus larger areas under sIRMDs than under tIRMDs. For each IRMD, we calculated the index of clustering for each genet as the count of the numbers of ramets from the same genet within the IRMD. Similarly, the index of intermingling for each genet was given by counts of ramets involving different genets within the IRMD.

The size of genets was calculated in two ways. First, we tallied the number of ramets per genet (MLL). Second, we estimated the area occupied by each genet by assuming that each ramet occupied a fixed area and then summing the area occupied by all ramets per genet. For this calculation, we superimposed a rectangular grid of cells over the population with resolution $30 \mathrm{~cm} \times 30 \mathrm{~cm}$. Ramets were assumed to occupy a square within this grid with sides equal to $2 \times$ sIRMD. The area occupied per genet was then the sum of all grid cells occupied per genet. Overlapping cells occupied by more than one ramet per genet were only counted once. Using this approach, two genets with the same number of ramets but with different patterns of dispersion (e.g. a tightly clustered genet versus a more widely dispersed genet) would be associated with different areal measurements. Calculations were repeated for the ilRMD and tIRMD.

\subsection{Predicted and estimated rates of selfing}

\subsubsection{Predicted selfing rates}

Selfing rates were predicted from the spatial distribution of genets (MLLs), the flowering phenology of ramets within genets and the 
inferred pollen dispersal kernel. Our predictions are based on the assumption that the selfing rate is proportional to the fraction of seeds that were likely to have been pollinated by other ramets in the genet based on these spatial and temporal patterns. Note that these calculations assume that male flowers are equivalent in their pollen production and in their ability to attract pollinators. The calculations presented here were based on ramet-level interactions. The calculated values were then averaged across the ramets per genet in an attempt to predict whole-clone selfing rates. In particular, we assumed that the amount of self-pollen arriving at the stigmas of the ramets comprising a genet $G, N\left(s_{G}\right)$, was proportional to the number of simultaneously open female and male flowers on pairs of ramets $i$ and $j$ within the genet and their spatial proximities:

$$
N\left(s_{G}\right) \propto \sum_{d}\left(S_{i j d} \cdot D_{i j d}\right)
$$

where $\boldsymbol{S}$ and $\boldsymbol{D}$ define the temporal and spatial intersection of female and male flowering among ramets within genets. Specifically, $S$ and $D$ are strictly upper triangular matrices with dimensions:

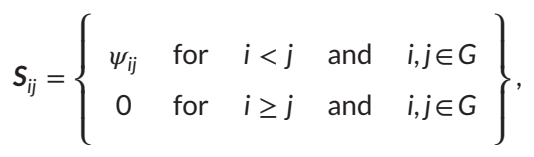

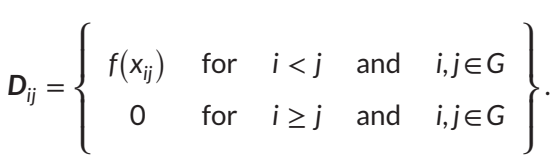

We included only the upper triangular from both matrices to account for the fact that selfing in S. latifolia cannot occur within ramets and cannot occur reciprocally between different ramets (because donor and recipient ramets cannot simultaneously express both sex functions), such that each pairwise selfing interaction was only counted once-for the interaction between the ramet in male phase and the ramet in female phase). The first matrix $\boldsymbol{S}$ specifies the intersection of female and male flowering among the ramets within genet $G$ on day $d$. Thus, for a given day $d$,

$$
\psi_{i j}=f_{i} \cdot \mathrm{cm}_{j}
$$

where $f_{i}$ is the number of female flowers produced by ramet $i, m_{j}$ is the number of male flowers produced by ramet $j$ and $c$ is a constant that scales male flower number to the number of pollen grains transferred to female flowers. For the calculations presented here, we set $c=1$. The second matrix $D$ weights the values in $S$ by the probability of pollen dispersal between ramets $i$ and $j$ separated by distance $r$. We assumed that this distance followed an exponential distribution with $f\left(\lambda, r_{i j}\right)=\lambda e^{(-\lambda r)}$.

As for predicted selfing, we assumed that the outcrossing rate per genet was proportional to the number and proximity of ramets from other genets (i.e. $\left.G^{\prime}\right)$. For each ramet, then the number of outcross pollen grains received per genet $G, N\left(t_{G}\right)$, was expected to be proportional to:

$$
N\left(t_{G}\right) \propto \sum_{g \in G^{\prime}} \sum_{d}\left(T_{i g d} \cdot D_{i g d}\right)
$$

where $\boldsymbol{T}$ and $\boldsymbol{D}$ are:

$$
T_{i g}=\left[\tau_{i g} \text { for } i \in G, \quad g \in G^{\prime}\right], \quad D_{i g}=\left[f\left(\lambda, r_{i g}\right) \text { for } i \in G, \quad g \in G^{\prime}\right],
$$

and

$$
\tau_{\text {ig }}=f_{i} \cdot \mathrm{cm}_{g}
$$

where $f, m$ and $c$ are as defined above.

We assumed that selfing rates per $M L L, s_{G}$, were determined by the proportion of self-pollen arriving at stigmas, and therefore, that:

$$
s_{G}=\frac{N\left(s_{G}\right)}{N\left(s_{G}\right)+N\left(t_{G}\right)}
$$

We calculated one estimate of $s_{G}$ for each seed screened for selfing rate. Additional details and the corresponding $\mathrm{R}$ scripts are given in Supporting Information: Methods S2.

\subsubsection{Observed selfing rates}

All seven loci were used to estimate the multilocus outcrossing rate $\left(t_{m}\right)$ at the ramet level using the multilocus estimation software MLTR (v. 3.4; Ritland, 2002). Selfing rates were calculated as $1-t_{m}$, and these values were then averaged across all ramets per genet (MLL) to estimate genet-level selfing rates. The mean number of offspring per ramet used for the calculations of $t_{m}$ was 2 (range $=1-7$ ). Because the genotype of the mother was known, selfing versus outcrossing events could be inferred from single progeny. Selfing rates were calculated for 148 families from a total of 353 seed genotypes.

\subsection{Statistical analyses}

\subsubsection{Clonal expansion and genet intermingling}

Our indices of intermingling and clustering can only increase with genet size, as they are summed across ramets per genet (MLL), but the rates at which intermingling and clustering increase with genet size might differ. For example, larger genets might be more clustered and less intermingled than smaller genets. Accordingly, the association between genet size (the number of ramets per genet) and patterns of genet intermingling versus clustering was evaluated using a generalized linear mixed-effect model, calculated using the glmer function from the LME4 package (Bates, Mächler, Bolker, \& Walker, 2015) in R. The cumulative number of spatially overlapping ramet pairs was modelled as the interaction between the type 
of overlap (intermingling among ramets or clustering within genets; i.e. our indices of intermingling and clustering as defined above) and the number of ramets per genet. The model was calculated using a Poisson error distribution with log link function. Because there were two measurements per genet (intermingling and clustering), which are not independent, we included genet as a random effect in the model. This model failed to converge when ilRMD and tIRMD were used to scale the area occupied by genets; for calculations of intermingling involving these spatial scales, we used a linear mixed model with log-transformed index values as the dependent variable. This model was calculated using the Imer function from the LME4 package (Bates et al., 2015) in R. Tests of significance for main effects were calculated using type III sums of squares implemented in the ANOVA function from the CAR package (Fox \& Weisberg, 2011). As a further test of the prediction that intermingling increases with clonal expansion, we also calculated a GLM for which the proportion of non-self versus self-ramets within the IRMD was the response variable and the number of ramets per genet was the predictor variable. The analysis was done using the quasibinomial setting to account for over-dispersion. To improve model fit, the number of ramets per genet was log-transformed. Both analyses included only genets comprised of more than one ramet. This was done to remove bias that might have arisen because genets comprised of only one ramet cannot spatially overlap with other ramets from the same genet but can overlap with ramets from other genets.

\subsubsection{Genet size and selfing rates}

We evaluated the correspondence between genet size and estimated rates of selfing using multiple regression. We were specifically interested in how measures of clone size were associated with selfing rates, but our two measures of clone size (number of ramets per genet and genet area) were correlated with one another (Pearson $r=0.62, d f=53, p<0.001,95 \% \mathrm{Cl}=0.42,0.76$ ). Therefore, to avoid collinearity among independent variables, we used the residuals of the regression of genet area on the number of ramets per genet in our analysis instead of genet area. Positive values of these residuals indicate genets that are more dispersed for a given number of ramets and negative values indicate genets that are more clustered. The independent variables for this analysis were the number of ramets per genet (MLL), the residuals described above and their interaction. The dependent variable was the estimated selfing rate averaged across ramets per genet. Leastsquares calculations for this model were weighted by the number of seeds screened per genet under the assumption that the accuracy of our estimates increased with family size. Because the calculation of genet area depended on our assumption of mating neighbourhood size (IRMD), and because we evaluated three different sizes of mating neighbourhoods (sIRMD, iIRMD and tIRMD), we report model results for each neighbourhood size. Tests of significance were carried out using type III sums of squares using the ANOVA function from the CAR package.
To evaluate whether rates of selfing could be predicted from the observed patterns of pollen dispersal and the temporal and spatial overlap in sex functions among ramets within genets, we conducted parallel analyses with those used for observed patterns of selfing. First, we used weighted multiple regression to evaluate the association between clonal expansion and predicted patterns of selfing. For this analysis, the dependent variable was the predicted proportion of self-pollen landing on stigmas, $s_{G}$, and the independent variables were the number of ramets per genet, the residuals of the regression of genet area on the number of ramets per genet and their interaction. The number of seeds per genet for which $s_{G}$ was calculated was used to weight the analysis. Second, we calculated the Pearson correlation between observed and predicted patterns of selfing per genet, again weighting the analysis by the number of seeds screened per genet. Because predicted patterns of selfing were based on the spatial distribution of ramets within genets, the temporal overlap in female and male function within genets, and the estimated pollen dispersal kernel, a positive correlation between predicted and observed selfing would indicate that patterns of selfing were driven by the spatial and temporal patterns of overlapping sex phases within genets.

\subsubsection{Genet size, male investment and siring success}

The total number of seeds sired per genet was modelled as the linear combination of the number of ramets per genet and the residuals of the regression of genet area on the number of ramets per genet, using Poisson regression. Residuals were used in this analysis for the same reasons as those given for tests of the association between clone size and selfing rates. Because sires were assigned with varying degrees of confidence, we calculated the sum of the probabilities of assigned sire genets and used these sums to weight the Poisson regression. The final model was calculated using the quasi-Poisson setting to account for overdispersion. Significance of the independent variables was calculated using type III tests using the ANOVA function from the CAR package. Because calculations of genet area depended on our assumption of mating neighbourhood size, we report model results for each neighbourhood size (sIRMD, iIRMD, tIRMD).

Genet size and male investment should be positively associated with one another. Accordingly, it was possible that the obtained association between genet size and siring success was driven by an underlying association with male investment. To account for this possibility, we compared results of the Poisson regression between genet size and siring success outlined above with the results of a Poisson regression involving male investment as an independent variable. In particular, we modelled the association between the total number of seeds sired per genet as the linear combination of the total number of male flowers per genet and the residuals of the regression of genet area on the number of ramets per genet. As for the previous analysis, the sum of the 
probabilities for genets assigned as sires was used to weight the regression. Models involving genet size and male investment were compared using AIC scores.

To test whether the association between male investment and siring success was linear, we assumed that all male flowers of S. latifolia entail an equal investment in male reproductive function. Accordingly, the total number of male flowers produced per genet was used as our measure of male investment. To evaluate whether the association between total male investment (TMI) per genet and our index of siring success (as defined in the preceding paragraph) was linear, as predicted, or nonlinear, we fitted each model and compared their fits by plotting observed siring success per genet versus the siring success predicted by each model. Both models were calculated using the nls function in R. The linear model was calculated as siring success $\sim a+b \times \mathrm{TMI}$, where $a$ is a constant and $b$ is the slope parameter. The nonlinear model was calculated as siring success $\sim a+\mathrm{TMl}^{c}$, where $c$ is the gain curve parameter (Charnov, 1979). Both the linear and nonlinear models were weighted by our index of confidence in siring per genet. Model results were calculated using nonlinear least squares using the nls function in R. We compared the results of each model by calculating AIC scores. Details for all statistical analyses, including the R scripts used for analysis, are provided in Supporting Information: Methods S3.

\section{$3 \quad$ RESULTS}

Genet (MLL) size ranged from 1 to 35 ramets with a median genet size of 1 ramet, indicating that the population consisted mostly of small genets but also included a small number of large genets (Figure 1 inset). Genets tended to be spatially localized but interspersed with ramets from other genets (Figure 1). However, several genets spanned larger distances in the population, typically consisting of a cluster of ramets in one area and isolated ramet(s) elsewhere in the population. The maximum distance between two ramets within a single genet was $61.9 \mathrm{~m}$; however, most genets spanned much smaller distances. Over short distances $(<1.5 \mathrm{~m})$, more than $20 \%$ of ramets were members of the same genet. However, at distances of $5 \mathrm{~m}$ fewer than $5 \%$ of ramets were part of the same genet, and at distances of $20 \mathrm{~m}$ fewer than $1 \%$ of ramets were part of the same genet.

\subsection{Paternity and inter-ramet mating distances}

Most of the genotyped seeds (301 of 358) were assigned to one or more sires. The majority of these seeds (213 of 301 ) were assigned a single siring MLL with an estimated probability of $100 \%$; 216 of 301 seeds were assigned to a single siring MLL with greater than 95\% probability. The remaining 85 seeds were assigned to sires with probabilities ranging from 0.01 to $0.94(M=0.25 \pm 0.22 S D)$. For the subset of 216 seeds assigned to a single siring MLL with high probability, pollen dispersal was inferred to have occurred over a broad



FIGURE 1 Map of the 506 ramets representing 210 genets in the study population (axes indicate distance in meters). Different genets (MLLs) have unique combinations of colour and symbol and are joined by lines linking the ramets at the exterior of each genet. Genets comprised of a single ramet are indicated by black squares. Inset: the frequency distribution of genet sizes (measured as the number of ramets per genet) in the population 
range of distances. The estimated value of the rate parameter for the pollen dispersal kernel (here, the negative exponential distribution) was 0.03 , corresponding with substantial pollen dispersal over distances greater than $10 \mathrm{~m}$ (Supporting Information: Methods S1, Figure S1). The $10 \%, 25 \%$ and $50 \%$ quantiles (i.e. the values of the inter-ramet mating distances used in the calculations of clonal intermingling and clone area) were as follows: $10 \%=$ sIRMD $=1.06 \mathrm{~m}$ (95\% Cl: 0.62, $1.47 \mathrm{~m}) ; 25 \%$ = ilRMD = $4.14 \mathrm{~m}$ (95\% Cl: 2.12, $6.29 \mathrm{~m})$; $50 \%=\mathrm{tIRMD}=13.9 \mathrm{~m}(95 \% \mathrm{Cl}: 10.1,16.8 \mathrm{~m})$. The mean observed inter-plant mating distance was $15.10 \pm 0.95 \mathrm{~m} \mathrm{SE}$. Average inter-ramet mating distances therefore exceeded the typical distance separating ramets of the same genet, as described in the preceding paragraph.

\subsection{Genet size and intermingling}

We found positive associations between the number of ramets per genet, and the patterns of clonal intermingling and spatial clustering
(Figure 2). Not surprisingly, genets with more ramets were more likely to have been both more intermingled with other genets and more clustered with other ramets from the same genet, and this effect depended on the size of the IRMD used to define the size of mating neighbourhoods. If we assumed that ramets occupied areas corresponding with much shorter than average pollen dispersal distances (sIRMD), smaller clones tended to be more intermingled than clustered, but this pattern was reversed for larger clones, which tended to be more clustered than intermingled (Figure 2a). By contrast, under assumptions for patterns of spatial occupancy that more closely corresponded to typical pollen dispersal distances, clones of all sizes tended to be more intermingled than clustered (tIRMD; Figure 2e). However, for all spatial scales of genet occupancy considered here, the number of pairwise occurrences of ramets within the IRMD was influenced by the interaction between genet size and the type of ramet pair (i.e. self vs. non-self; Table 1). This was driven by steeper associations between genet size and clustering than between genet size and intermingling (Figure 2a,c,e). As a result, there
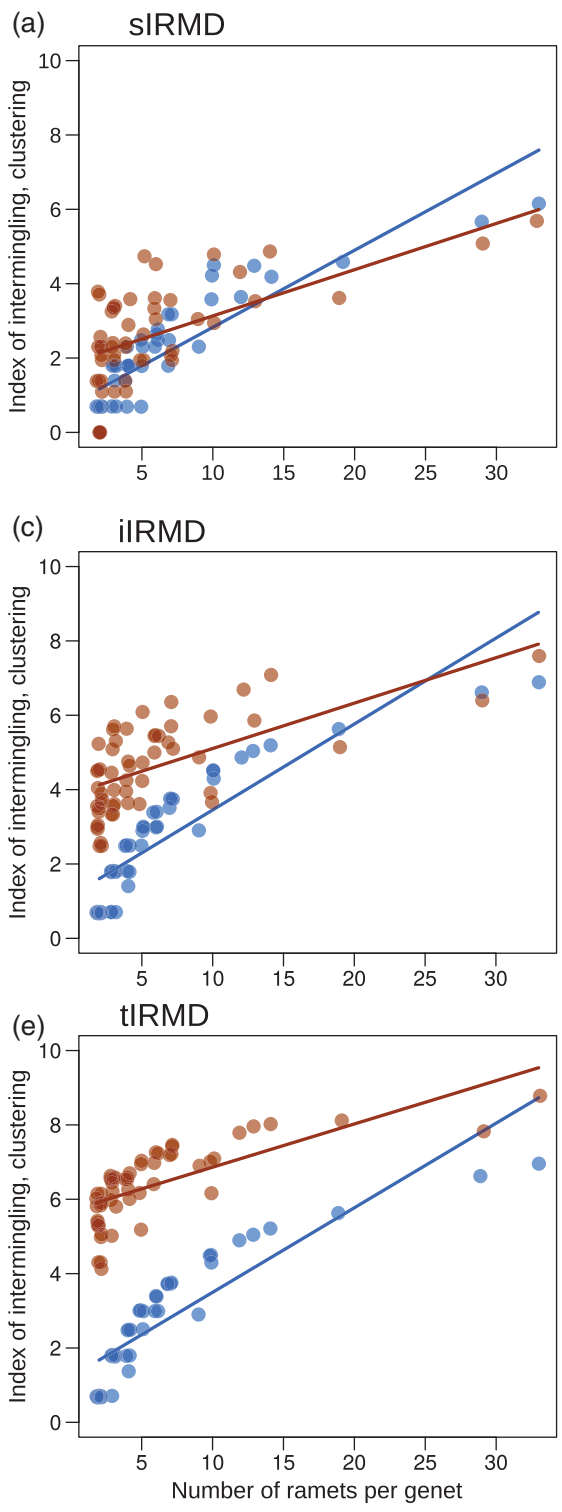
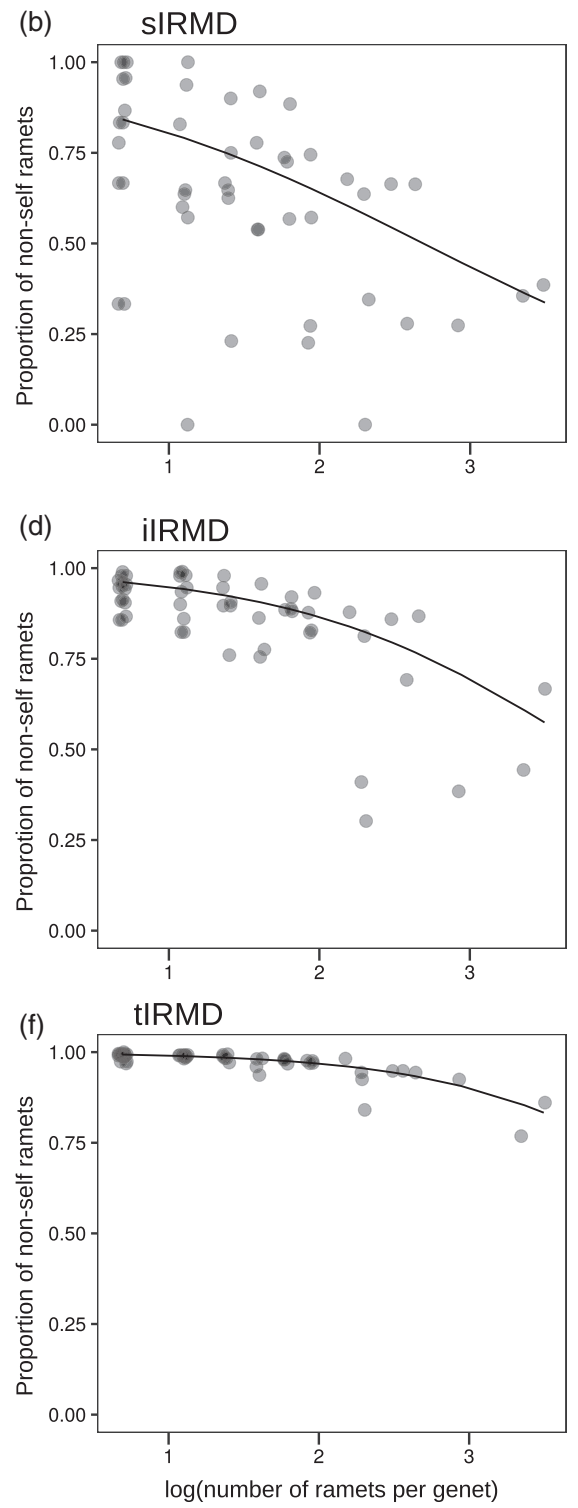

FIGURE 2 Patterns of clonal intermingling in a population of Sagittaria latifolia. Intermingling (red dots) was measured as the sum of the number of non-self ramets within the mating neighbourhoods of the ramets within each genet, where mating neighbourhoods were defined by the shape of the pollen dispersal kernel inferred from paternity analysis. Clustering (blue dots) was measured as the sum of the number of self-ramets within the mating neighbourhoods of the ramets within each genet. The spatial scales used to define the space occupied by ramets within genets were determined by the quantiles of inferred pollen dispersal distances ( $a \&$ b: $s I R M D=1.06 \mathrm{~m}, \mathrm{c} \& \mathrm{~d}$ : ilRMD $=4.13 \mathrm{~m}$, e \& f: tIRMD = $13.9 \mathrm{~m}$ ). Regardless of the spatial scales used to define the space occupied by ramets within genets, larger genets tended to have proportionally more self-ramets within their local mating neighbourhoods, although this increase in the proportion of self-ramets was weak when we assumed that ramets occupied areas corresponding with the median pollen dispersal distance (i.e. tIRMD). Lines indicate results of the linear mixedeffects model (a, c \& e) and the GLM (b, $d \& f$ ) used for examining patterns of intermingling versus clustering 
TABLE 1 The number of pairwise occurrences of ramets in a population of the clonal plant Sagittaria latifolia that occurred within mating neighbourhoods was influenced by an interaction between the type of ramet pair involved (self vs. non-self) and the size of the genet (measured as ramet number) for all assumptions of mating neighbourhood size (as determined by inter-ramet mating distances: short $=$ sIRMD, intermediate $=$ iIRMD, typical $=$ tIRMD). Parameter estimates, their standard errors and Wald chi-square test are reported from generalized linear mixed-effects models (sIRMD) and linear mixed-effects models (ilRMD and tIRMD)

\begin{tabular}{|c|c|c|c|c|c|c|}
\hline \multirow[b]{2}{*}{ Effect } & \multicolumn{2}{|l|}{ Short (sIRMD) } & \multicolumn{2}{|c|}{ Intermediate (iIRMD) } & \multicolumn{2}{|c|}{ Typical (tIRMD) } \\
\hline & Estimate $\pm S E$ & $\chi^{2}$ & Estimate $\pm S E$ & $\chi^{2}$ & Estimate $\pm S E$ & $\chi^{2}$ \\
\hline Intercept & $1.87 \pm 0.16$ & $128.5^{* * *}$ & $3.88 \pm 0.16$ & $616.7^{* * *}$ & $5.70 \pm 0.13$ & $1.90 \times 103^{* * *}$ \\
\hline Ramet type (ref. = self) & $-1.04 \pm 0.07$ & $243.9^{* * *}$ & $-2.74 \pm 0.18$ & $239.2^{* * *}$ & $-4.48 \pm 0.12$ & $1.51 \times 103^{* * *}$ \\
\hline Genet size & $0.14 \pm 0.02$ & $57.9^{* * *}$ & $0.12 \pm 0.02$ & $42.9^{* * *}$ & $0.12 \pm 0.02$ & $55.2^{* * *}$ \\
\hline Ramet type $\times$ genet size & $0.05 \pm 0.00$ & $282.9^{* * *}$ & $0.11 \pm 0.02$ & $26.6^{* * *}$ & $0.11 \pm 0.01$ & $65.6^{* * *}$ \\
\hline
\end{tabular}

${ }^{* * *} p<0.001$.

TAB LE 2 Variation in observed and predicted rates of selfing in a population of the clonal plant Sagittaria latifolia was influenced by genet size (measured as the number of ramets per genet; observed selfing) and by interactions between genet size and the residuals from the regression of genet area on the number of ramets per genet under assumptions of smaller mating neighbourhood sizes (sIRMD and ilRMD, corresponding with the 0.10 and 0.25 quantiles of inferred inter-ramet mating distances). Under assumptions corresponding with average mating neighbourhood sizes (tIIRMD), patterns of predicted selfing were influenced by variation in genet size. Parameter estimates, their standard errors and F-statistics (with numerator and denominator degrees of freedom) calculated using type III sums of squares are reported from linear models

\begin{tabular}{|c|c|c|c|c|c|c|}
\hline \multirow[b]{2}{*}{ Effect } & \multicolumn{2}{|l|}{ Short (sIRMD) } & \multicolumn{2}{|c|}{ Intermediate (ilRMD) } & \multicolumn{2}{|l|}{ Typical (tIRMD) } \\
\hline & Estimate $\pm S E$ & F-test & Estimate $\pm S E$ & $F$-test & Estimate $\pm S E$ & F-test \\
\hline \multicolumn{7}{|l|}{ Observed selfing } \\
\hline Intercept & $\begin{array}{l}4.29 \times 10^{-2} \\
\pm 4.48 \times 10^{-2}\end{array}$ & $F_{1,51}=0.92$ & $\begin{array}{l}7.14 \times 10^{-2} \\
\pm 4.22 \times 10^{-2}\end{array}$ & $F_{1,51}=2.87$ & $\begin{array}{l}7.04 \times 10^{-2} \\
\pm 3.74 \times 10^{-2}\end{array}$ & $F_{1,51}=3.53$ \\
\hline Area (residuals) & $\begin{array}{l}-1.97 \times 10^{-2} \\
\pm 1.47 \times 10^{-2}\end{array}$ & $F_{1,51}=1.79$ & $\begin{array}{l}-1.55 \times 10^{-3} \\
\pm 1.80 \times 10^{-3}\end{array}$ & $F_{1,51}=0.74$ & $\begin{array}{l}-3.04 \times 10^{-4} \\
\pm 2.02 \times 10^{-4}\end{array}$ & $F_{1,51}=2.26$ \\
\hline Genet size & $\begin{array}{l}1.27 \times 10^{-2} \\
\pm 4.48 \times 10^{-3}\end{array}$ & $F_{1,51}=8.10^{* *}$ & $\begin{array}{l}8.45 \times 10^{-3} \\
\pm 3.88 \times 10^{-3}\end{array}$ & $F_{1,51}=4.73^{*}$ & $\begin{array}{l}8.34 \times 10^{-3} \\
\pm 2.71 \times 10^{-3}\end{array}$ & $F_{1,51}=9.48^{* *}$ \\
\hline Area $\times$ genet size & $\begin{array}{l}1.52 \times 10^{-3} \\
\pm 1.04 \times 10^{-3}\end{array}$ & $F_{1,51}=2.12$ & $\begin{array}{l}6.71 \times 10^{-5} \\
\pm 1.60 \times 10^{-4}\end{array}$ & $F_{1,51}=0.18$ & $\begin{array}{l}2.55 \times 10^{-5} \\
\pm 1.50 \times 10^{-5}\end{array}$ & $F_{1,51}=2.90$ \\
\hline \multicolumn{7}{|l|}{ Predicted selfing } \\
\hline Intercept & $\begin{array}{l}-9.25 \times 10^{-3} \\
\pm 2.69 \times 10^{-3}\end{array}$ & $F_{1,54}=11.81^{* *}$ & $\begin{array}{l}-8.06 \times 10^{-3} \\
\pm 2.62 \times 10^{-3}\end{array}$ & $F_{1,54}=9.50^{* *}$ & $\begin{array}{l}-4.50 \times 10^{-3} \\
\pm 2.39 \times 10^{-3}\end{array}$ & $F_{1,54}=3.55$ \\
\hline $\begin{array}{r}\text { Genet area } \\
\text { (residuals) }\end{array}$ & $\begin{array}{l}-2.33 \times 10^{-3} \\
\pm 8.07 \times 10^{-4}\end{array}$ & $F_{1,54}=8.34^{* *}$ & $\begin{array}{l}-1.85 \times 10^{-4} \\
\pm 8.74 \times 10^{-5}\end{array}$ & $F_{1,54}=4.50^{*}$ & $\begin{array}{l}7.54 \times 10^{-6} \\
\pm 9.59 \times 10^{-6}\end{array}$ & $F_{1,54}=0.62$ \\
\hline Genet size & $\begin{array}{l}3.34 \times 10^{-3} \\
\pm 2.72 \times 10^{-4}\end{array}$ & $F_{1,54}=150.92^{* * *}$ & $\begin{array}{l}3.14 \times 10^{-3} \\
\pm 2.46 \times 10^{-4}\end{array}$ & $F_{1,54}=162.4^{* * *}$ & $\begin{array}{l}2.62 \times 10^{-3} \\
\pm 1.80 \times 10^{-4}\end{array}$ & $F_{1,54}=211.90^{* * *}$ \\
\hline Area $\times$ size & $\begin{array}{l}1.79 \times 10^{-4} \\
\pm 5.83 \times 10^{-5}\end{array}$ & $F_{1,54}=9.38^{* *}$ & $\begin{array}{l}2.00 \times 10^{-5} \\
\pm 8.24 \times 10^{-6}\end{array}$ & $F_{1,54}=5.91^{*}$ & $\begin{array}{l}-1.46 \times 10^{-6} \\
\pm 8.12 \times 10^{-7}\end{array}$ & $F_{1,54}=3.23$ \\
\hline
\end{tabular}

${ }^{*} p<0.05 ;{ }^{* *} p<0.01 ;{ }^{* * *} p<0.001$

were negative associations between genet size and the proportion of ramets intermingled with other genets (sIRMD: $t=-6.38$, $p<0.001$; ilRMD: $t=-7.80, p<0.001$; tIRMD: $t=-14.4, p<0.001$; Figure $2 b, d, f)$.

\subsection{Predicted and estimated selfing rates}

The number of ramets per genet was positively associated with estimated (observed) rates of selfing for all assumptions of spatial patterns of genet occupancy (i.e. as defined by mating neighbourhood size; Table 2). There was no effect of the residuals from the regression of genet area on the number of ramets per genet for any of the assumptions for the spatial patterns of genet occupancy (Table 2), and there was no interaction between these residuals and the number of ramets per genet (Table 2). However, the relationship between the number of ramets per genet and selfing rates was weak (overall model sIRMD: $R^{2}=0.12$; ilRMD: $R^{2}=0.11$; tIRMD: $\left.R^{2}=0.13\right)$, and selfing rates for small genets were highly variable (Figure 3). 
The association between the number of ramets per genet and predicted selfing was positive for all assumptions for the spatial patterns of genet occupancy (Table 2). However, under the assumption that ramets occupy patches that correspond with short and intermediate pollen dispersal distances, these patterns were obscured by positive interactions between the residuals from the regression of genet area on the number of ramets per genet and the number of ramets per genet (Table 2). For the assumption that ramets occupy larger patches, there was no significant effect of the residuals from the regression of genet area on the number of ramets per genet or an interaction between these residuals and the number of ramets per genet (Table 2). These broadly similar patterns for observed and predicted patterns of selfing with measures of clone size yielded a positive, albeit weak, association between them (Pearson correlation: $r=0.24, F_{1,54}=4.72, p<0.05$ ).

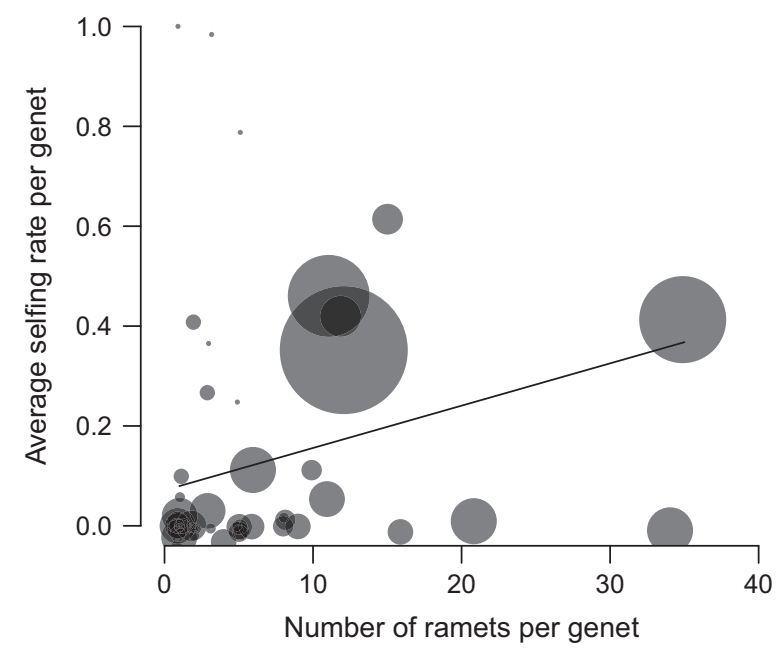

FIGURE 3 Patterns of selfing as a function of genet size (number of flowering ramets per MLL) in a natural population of Sagittaria latifolia. Point size is proportional to the number of seeds per MLL screened for selfing rates. The line indicates the slope of the weighted regression of average selfing rate on genet size, with the number of seeds screened per MLL used as the weighting variable and using the ilRMD as the spatial scale for calculating genet area (see Methods for additional model details)

\subsection{Genet size and siring success}

The number of ramets per genet was positively associated with siring success for all assumptions of spatial patterns of genet occupancy (Table 3; Figure 4). Siring success was not associated with the residuals from the regression of genet area on the number of ramets per genet (Table 3), or the interaction between these residuals and the number of ramets per genet (Table 3). This indicates that the increased siring success of large clones was driven mainly by the number of ramets per genet and not by the patterns of ramet dispersion.

The association between genet size and siring success might have been driven by an underlying association between genet size and male investment. Male investment was strongly correlated with genet size (linear model: male flowers per genet $=1.9+5.4 \times$ number of ramets per genet, $R^{2}=0.88, F_{1,42}=320.8, p<0.001$;

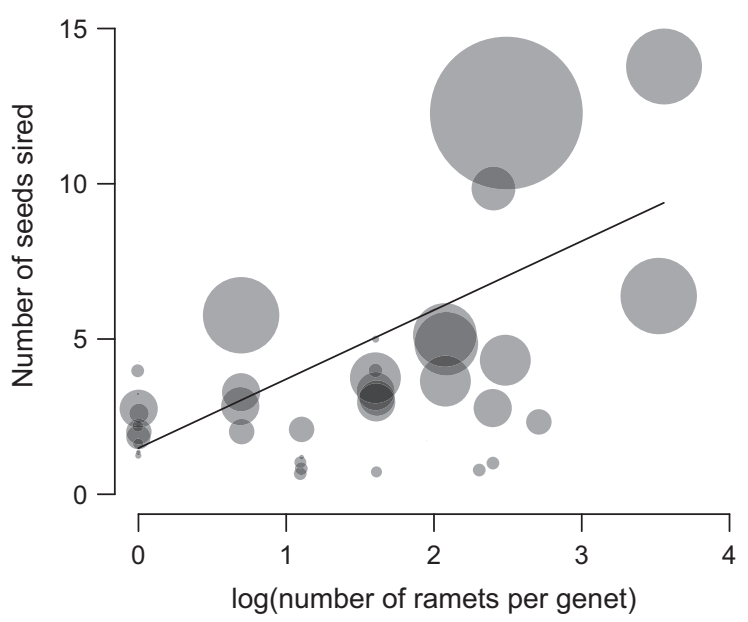

FIGURE 4 Association between siring success and genet size (number of flowering ramets per MLL) in a natural population of Sagittaria latifolia. Point size is proportional to our cumulative measure of confidence in siring (the sum of the probabilities of paternity per assigned sire, calculated using COLONY2). For plotting, the number of flowering ramets per genet was log-transformed and the line indicates the slope of a weighted linear regression of siring success on the log(number of flowering ramets per genet) using the ilRMD as the spatial scale for calculating genet area

TAB LE 3 Siring success per genet in a population of the clonal plant Sagittaria latifolia was influenced by variation in genet size (measured as the number of ramets per genet) for all assumptions of mating neighbourhood size (as determined by inter-ramet mating distances: short $=$ sIRMD, intermediate = ilRMD, typical = tIRMD). Parameter estimates, their standard errors and likelihood-ratio test chi-square values are reported from Poisson regression. Parameter estimates for genet area, genet size and their interaction are scaled by $10^{2}$

\begin{tabular}{|c|c|c|c|c|c|c|}
\hline \multirow[b]{2}{*}{ Effect } & \multicolumn{2}{|l|}{ Short (sIRMD) } & \multicolumn{2}{|c|}{ Intermediate (iIRMD) } & \multicolumn{2}{|l|}{ Typical (tIRMD) } \\
\hline & Estimate $\pm S E$ & $\chi^{2}$ & Estimate $\pm S E$ & $\chi^{2}$ & Estimate $\pm S E$ & $\chi^{2}$ \\
\hline Intercept & $1.05 \pm 0.17$ & NA & $1.27 \pm 0.17$ & NA & $1.24 \pm 0.13$ & NA \\
\hline $\begin{array}{r}\text { Genet area } \\
\text { (residuals) }\end{array}$ & $-2.46 \pm 4.19$ & 0.35 & $-0.22 \pm 0.42$ & 0.28 & $-0.05 \pm 0.04$ & 1.73 \\
\hline Genet size & $6.17 \pm 1.60$ & $15.60^{* * *}$ & $3.75 \pm 1.58$ & $5.42^{*}$ & $4.13 \pm 0.81$ & $21.7^{* * *}$ \\
\hline Area $\times$ size & $0.52 \pm 0.33$ & 2.52 & $0.02 \pm 0.05$ & 0.15 & $0.00 \pm 0.00$ & 2.89 \\
\hline
\end{tabular}

${ }^{*} p<0.05 ;{ }^{* * *} p<0.001$. 


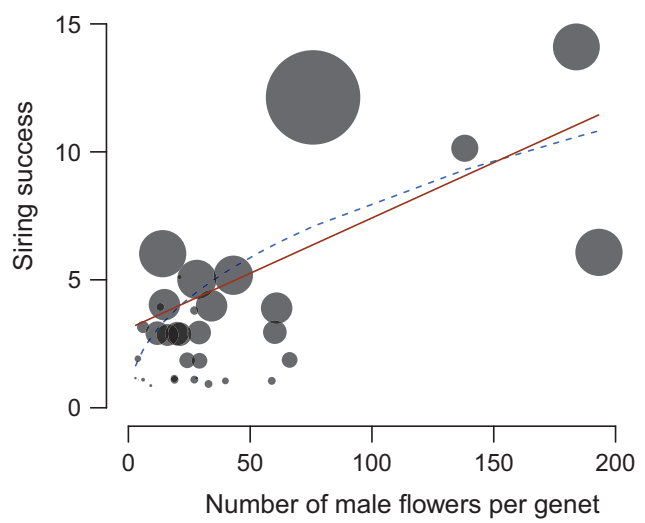

FIGURE 5 Association between the total investment in male function per genet (measured as the number of male flowers per $M L L)$ and siring success in a natural population of Sagittaria latifolia. The nonlinear model (power function) was associated with a lower AIC score than the linear model. Lines were calculated from the fitted parameter values from each model. Point size is proportional to our cumulative measure of confidence in siring (the sum of the probabilities of paternity per assigned sire, calculated using COLONY2)

Figure S2). Poisson regression between siring success and male investment provided substantially lower AIC scores than the Poisson regression reported above for genet size and for all assumptions of spatial patterns of genet occupancy (sIRMD: $\triangle \mathrm{AIC}=26.71$; iIRMD: $\triangle \mathrm{AIC}=12.5$; tIRMD: $\triangle \mathrm{AIC}=10.7$ ). Thus, increased siring by large clones appeared to have been driven by their greater investment in male function than smaller clones. Indeed, there was a positive linear association between male investment and siring success (siring success $\sim a+b \times \mathrm{TMI} ; a=3.09, t_{a}=4.61, p_{a}<0.001, b=0.04, t_{b}=5.34$, $\left.p_{b}<0.001\right)$. However, the nonlinear model provided qualitatively similar fits to the data (Figure 5; Figure S3), and was associated with substantially lower AIC ( $\triangle$ AIC $=-9.43$ ). The model parameters for the nonlinear fit indicated strongly diminishing returns on male investment (siring success $\sim a+\mathrm{TMI}^{c} ; a=-0.19, t_{a}=-0.24, p_{a}>0.80$, $\left.c=0.46, t_{c}=16.6, p_{c}<0.001\right)$. This result was driven by a single MLL with a TMI of 76 flowers that occurred in the highest density patch in the population (the MLL indicated by beige circles within the region bounded by $x=5-11 \mathrm{~m}, y=15-18 \mathrm{~m}$ in Figure 1). Exclusion of this MLL from the analysis yielded equivocal evidence for a linear versus nonlinear association between male investment and siring success $(\triangle \mathrm{AIC}=0.02)$. Taken together, these data indicate that large clones have greater siring success than small clones, but that this relationship might weaken as clones become very large.

\section{DISCUSSION}

When clones become intermingled, clonal expansion is expected to yield increased opportunities for outcrossed siring success with minimal costs to mating from increased rates of selfing (Van Drunen et al., 2015). In line with these expectations, we found that larger genets of S. latifolia had substantially greater siring success than smaller genets. However, large genets tended to be surrounded by more ramets from the same clone than smaller genets. This clonal clustering for larger compared to smaller genets was associated with a weak, positive association between clone size and rates of geitonogamous selfing. Even under assumptions of strong trade-offs between growth and reproduction (such that clones can have many ramets or have large reproductive output, not both), some increase in geitonogamous selfing rates is expected for larger clones (Van Drunen et al., 2015). Indeed, this pattern might explain the decelerating association between the production of male flowers per genet and siring success in the population. Taken together, our results broadly support the expectation that clonal expansion should yield increased mating success, but they also indicate that this increase is not monotonic-on a per-flower basis, smaller genets had greater siring success, on average, than larger genets. Below, we discuss our results in more detail and compare them to expectations and results from other studies of mating patterns in populations of clonal plants.

\subsection{Clonal intermingling}

For the population of S. latifolia studied here, mating neighbourhoods increased with genet size, but so did the proportion of neighbours that were part of the same genet. Indeed, the extent to which genets were spatially clustered was somewhat surprising (and see Yakimowski \& Barrett, 2014). In S. latifolia, genets disintegrate annually and clonal fragments can be dispersed. In the population studied here, spatially isolated ramets that were part of larger genets might have arisen from the dispersal of clonal propagules. Nevertheless, most genets were confined to a single patch within the population and there was an overall trend for the largest genets to be the most spatially clustered (measured in terms of the number of self-ramets within mating neighbourhoods). The positive association between clustering and genet size observed here is similar to observations from other plants capable of dispersing clonal propagules or fragments (e.g. Cymodocea nodosa, Ruggiero, Reusch, \& Procaccini, 2005) or, more generally, from plants with a 'guerrilla'-type clonal growth form (e.g. Sasa veitchii var. hirsuta, Matsuo et al., 2014). For example, Dioscorea japonica produces bulbils that are sometimes secondarily dispersed by rodents (Mizuki, Ishida, Tani, \& Tsumura, 2010). In that study, most nearest neighbours were not clone-mates, and on a proportional basis, there was still a positive association between genet size and clonal clustering (Mizuki et al., 2010), as in our study of S. Iatifolia. For extremely large genets, such patterns are inevitable, even for highly intermingled genets; if populations are dominated by one or a few large genets, ramets within those genets will tend to occur within each other's mating neighbourhoods.

Patterns of clustering versus intermingling are determined by the products of sexual and asexual recruitment. Given enough time, even clonal plants with 'phalanx'-type growth forms can become intermingled (e.g. Loh, Scarano, Alves-Ferreira, \& Salgueiro, 2015). Under benign glasshouse conditions, genets of $S$. Iatifolia can, after 
a single growing season, consist of more ramets than even the largest genet in the population studied here (Dorken \& Barrett, 2003). However, rates of clonal recruitment for S. latifolia are much lower under more natural conditions, even when above-ground competition is removed (Dorken \& Barrett, 2003), and the relative rates of sexual to clonal recruitment in S. latifolia are not known. The presence of a large number of genets comprised of single ramets in this study is consistent with, if not a recent flush of sexual recruitment, possibilities for clonal turnover. Indeed, population-level extirpation rates are reasonably high, particularly in monoecious populations (Dorken \& Barrett, 2003), suggesting that clonal turnover and sexual recruitment are important contributors to the structuring of natural populations (and see Diaz-Almela et al., 2007). In this population, a disturbance event that took place after our study was completed resulted in nearly complete clonal turnover and an increase in patterns of clonal clustering (Holt, Kwok, \& Dorken, 2019). The flip-side of this interpretation is that intermingling in S. latifolia increases over time, as the repeated establishment of new ramets displaces genets from their sites of origin. So, although clones might become more clustered as they become larger, this effect should diminish over time as opportunities for intermingling increase.

\subsection{Patterns of pollen dispersal}

Estimates from studies of pollen dispersal in animal-pollinated herbaceous plants involve a broad range of distances. Examples include pasque flower Pulsatilla vulgaris (mean within-population pollen dispersal distance estimated from seven populations $=4.98 \mathrm{~m}$, range of within-population averages $=2.66-9.49 \mathrm{~m}$; DiLeo, Holderegger, $\&$ Wagner, 2018), Centaurea corymbosa (mean $=21.6 \mathrm{~m}$; Hardy et al., 2004) and oxlip Primula elatior (two within-population pollen dispersal estimates = 6.9, 32.4 m; Van Rossum, Stiers, Van Geert, Triest, \& Hardy, 2011). We inferred a mean distance between mates of more than $15 \mathrm{~m}$, a value in the middle of the range reported for other animal-pollinated herbaceous plants. These estimates of pollen dispersal distances will have been influenced by a variety of ecological features of those populations, including plant densities (Schmitt, 1983), types of pollinators (Schmitt, 1980) and interactions with other plants that could have affected pollen carry-over, such as competition among plants for pollinator visitation (Campbell, 1985).

The outward expansion of plants that can occur via clonal growth is another one of these factors that is expected to enable increases in realized pollen dispersal distances (Van Drunen et al., 2015). Indeed, the mating benefits of clonal expansion and the concomitant increase in intermingling between plants are expected to accrue most strongly to plants with spatially restricted pollen dispersal. If pollen dispersal occurs over distances that do not exceed typical distances between ramets from the same genet, clonality should have positive effects on mating patterns (Van Drunen et al., 2015). Indeed, studies of pollen dispersal in two wind-pollinated clonal plants capable of extensive clonal intermingling have inferred remarkably short pollen dispersal distances (dwarf bamboo, S. veitchii var. hirsuta, mean pollen dispersal distances inferred from parentage analysis for a subset of single-ramet genets: 1.4 m; Matsuo et al., 2014; broadleaf cattail, Typha latifolia, mean pollen dispersal distances inferred from spatial analysis of seed set and supported from a wind-tunnel study: <2 m; Ahee et al., 2015; Pieper, 2018). The ability to become near neighbours with other genets via clonal expansion should enable these plants to continue to disperse pollen to other plants as they grow.

\subsection{Predicted and observed selfing}

Larger genets in the population studied here tended to have moderately higher rates of selfing than smaller clones. Because female and male sex phases within inflorescences rarely overlap, increased rates of selfing for larger clones are driven by inter-ramet geitonogamy, and thus also by overlap in sex phases among ramets. This finding is broadly consistent with model results predicting weak, positive associations between rates of geitonogamous selfing and clone size (Van Drunen et al., 2015). In their model, Van Drunen et al. (2015) assumed trade-offs between growth and reproduction such that clones could consist of many ramets or have large reproductive effort, not both. Although there are strong trade-offs between growth and reproduction in S. Iatifolia (Van Drunen \& Dorken, 2012), as shown in this study, large clones had greater total reproductive output than smaller clones. Indeed, size and reproductive output are expected to be positively correlated in natural populations, even in the presence of trade-offs (Weiner, Campbell, Pino, \& Echarte, 2009). For example, greater reproductive output of large clones could arise because they are older than small clones and/or they occur in nutrient-rich microsites.

The prevailing view in the literature over the past 30 years has been that clonal expansion should yield increased opportunities for geitonogamous pollen transfer and, therefore, increased rates of self-fertilization (Barrett, 2015; Charpentier, 2002; Handel, 1985; Silander, 1985; Vallejo-Marín et al., 2010). Early tests of this idea have involved plants with 'phalanx'-type growth forms (Handel, 1985). Evaluations of selfing rates for plants with 'guerrilla'type growth forms indicate that geitonogamous pollen transfer is not the primary contributor to selfing rates (Eckert, 2000), that intermingling of genets can be associated with low rates of selfing (Albert et al., 2008; but see Somme et al., 2014), and that larger genets do not necessarily have higher selfing rates than smaller genets (Matsuo et al., 2014 and see also Liao et al., 2009). Indeed, increases in geitonogamous pollen transfer resulting from clonal expansion are expected to be lower than those that would result from a similar increase in plant size for a non-clonal organism (Liao \& Harder, 2014; Vallejo-Marín et al., 2010; Van Drunen et al., 2015). With this in mind, although an increase in selfing rates for very large or isolated genets might be inevitable, for small- to medium-sized genets in the population studied here, selfing rates do not appear to be exclusively driven by variation in genet size. Indeed, the positive association between observed and predicted rates of selfing indicate that spatial relations among genets and 
the degree of temporal overlap in sex phases among ramets within genets affect rates of geitonogamous selfing. These are not surprising inferences, but they underscore the fact that mating patterns are driven by complex interactions among plants and their pollinators.

\subsection{Clonal expansion and fitness through male function}

An intriguing idea, particularly for clonal plants capable of fragmentation and the dispersal of vegetative propagules, such as S. Iatifolia, is that clonal expansion can result in 'mate finding' (Barrett, 2015). On the one hand, our results are consistent with this possibility; larger genets were, in absolute terms, intermingled with a larger number of other genets and had, on average, greater siring success than smaller genets. On the other hand, patterns of ramet dispersion did not have strong effects on siring success (i.e. the residuals from the regression of genet area on the number of ramets per genet did not appear to influence patterns of siring success), and there was some evidence that investment in male function per clone yielded decelerating mating benefits. So, does clonal growth benefit mating? The alternative to clonal growth is for plants to increase in size in one place, resulting in greater reproductive investment without any spatial separation among inflorescences. Under these conditions, reduced mating success via pollen discounting and/or self-fertilization is expected to result in more strongly diminishing fitness returns (Van Drunen et al., 2015) than for clonal phenotypes.

An important difference between our study and previous studies involving controlled experiments (Liao \& Harder, 2014) or simulated populations (Van Drunen et al., 2015) is that those previous studies made the simplifying assumption of equal reproductive investment among plants. However, modular growth means that larger plants (and genets) can have greater total reproductive investment than smaller plants. Our results indicate that this larger reproductive investment for larger clones can lead to somewhat higher rates of selfing than for smaller clones (but see Liao et al., 2009; Matsuo et al., 2014). Because selfing in S. latifolia should usually occur via inter-inflorescence geitonogamy (Dorken et al., 2002), even small increases in selfing rates should negatively affect siring opportunities via pollen discounting. Moreover, clonal expansion can yield decreased pollen export per flower (Liao \& Harder, 2014). Together, these effects could counteract benefits to mating success arising from greater intermingling by large clones and explain why siring success appeared to taper off for the clones with the largest investment in male function.

\section{CONCLUSIONS}

Increased selfing rates with clone size found here and in other studies, and expected a priori (Antonovics \& Levin, 1980), have led to the suggestion that there should be an optimal clone size that balances the positive effects of clonal expansion against the negative consequences of inbreeding (Silander, 1985). However, whether selfing increases with plant (clone) size is somewhat beside the point. It is clear that increased selfing should often accompany increases in plant size (and the number of ramets per clone), all else being equal (Charpentier, 2002). However, all else is not equal; because of the intermingling that is enabled by clonal growth, clonality is expected to weaken the association between plant size and the magnitude of self-fertilization, particularly if there are trade-offs between reproduction and growth (Van Drunen et al., 2015). Moreover, this view that clonal growth can interfere with mating ignores the potential contribution of clonal expansion to pollen dispersal. Because outward expansion and the subdivision of male function among ramets should enable higher rates of between-genet pollen transfer (Van Drunen et al., 2015), larger clones should have larger mating neighbourhoods than smaller clones. Our results were largely consistent with these joint effects of clonal expansion on selfing and siring success. When clones are intermingled, larger clones should have greater reproductive success through their female and male functions than smaller clones, even if these effects taper off for the largest clones.

\section{ACKNOWLEDGEMENTS}

We thank A. Bunbury-Blanchette for assistance in the field, K. Mamonova and B. Rüter for assistance in the laboratory, and J. Freeland and R. Franckowiak for advice. This research was supported by a Discovery Grant from the Natural Sciences and Engineering Research Council of Canada (NSERC) to M.E.D., a Humboldt Research Fellowship for Experienced Researchers to M.E.D. The authors declare no conflict of interest.

\section{AUTHORS' CONTRIBUTIONS}

S.S. collected the data and co-wrote the manuscript; M.v.K. and M.E.D. conceived of the study, analysed the data and co-wrote the manuscript.

\section{ORCID}

Mark van Kleunen (iD) https://orcid.org/0000-0002-2861-3701

Marcel E. Dorken iD https://orcid.org/0000-0001-7400-5136

\section{REFERENCES}

Ahee, J. E., Van Drunen, W. E., \& Dorken, M. E. (2015). Analysis of pollination neighbourhood size using spatial analysis of pollen and seed production in broadleaf cattail (Typha latifolia). Botany-Botanique, 93, 91-100. https://doi.org/10.1139/cjb-2014-0169

Albert, T., Raspé, O., \& Jacquemart, A.-L. (2008). Influence of clonal growth on selfing rate in Vaccinium myrtillus L. Plant Biology, 10, 643649. https://doi.org/10.1111/j.1438-8677.2008.00067.x 
Antonovics, J., \& Levin, D. A. (1980). The ecological and genetic consequences of density-dependent regulation in plants. Annual Review of Ecology and Systematics, 11, 411-452. https://doi.org/10.1146/annurev. es.11.110180.002211

Bailleul, D., Stoeckel, S., \& Arnaud-Haond, S. (2016). RClone: A package to identify multilocus clonal lineages and handle clonal data sets in R. Methods in Ecology and Evolution, 7, 966-970. https://doi. org/10.1111/2041-210x.12550

Barrett, S. C. H. (2002). Sexual interference of the floral kind. Heredity, 88, 154-159. https://doi.org/10.1038/sj.hdy.6800020

Barrett, S. C. H. (2015). Influences of clonality on plant sexual reproduction. Proceedings of the National Academy of Sciences of the United States of America, 112, 8859-8866. https://doi.org/10.1073/ pnas.1501712112

Bates, D., Mächler, M., Bolker, B., \& Walker, S. (2015). Fitting linear mixed-effects models using Ime4. Journal of Statistical Software, 67, 1-48.

Bolker, B. M. (2008). Ecological models and data in R. Princeton, NJ: Princeton University Press.

Campbell, D. R. (1985). Pollen and gene dispersal: The influences of competition for pollination. Evolution, 39, 418-431. https://doi. org/10.1111/j.1558-5646.1985.tb05678.x

Charnov, E. L. (1979). Simultaneous hermaphroditism and sexual selection. Proceedings of the National Academy of Sciences of the United States of America, 76, 2480-2484. https://doi.org/10.1073/ pnas.76.5.2480

Charpentier, A. (2002). Consequences of clonal growth for plant mating. Evolutionary Ecology, 15, 521-530. https://doi.org/10.1023/A:10160 57503722

Diaz-Almela, E., Arnaud-Haond, S., Vliet, M. S., Álvarez, E., Marba, N., Duarte, C. M., \& Serrão, E. A. (2007). Feed-backs between genetic structure and perturbation-driven decline in seagrass (Posidonia oceanica) meadows. Conservation Genetics, 8, 1377-1391. https://doi. org/10.1007/s10592-007-9288-0

DiLeo, M. F., Holderegger, R., \& Wagner, H. H. (2018). Contemporary pollen flow as a multiscale process: Evidence from the insect-pollinated herb, Pulsatilla vulgaris. Journal of Ecology, 106(6), 2242-2255. https:// doi.org/10.1111/1365-2745.12992

Dorken, M. E., \& Barrett, S. C. H. (2003). Life-history differentiation and the maintenance of monoecy and dioecy in Sagittaria latifolia (Alismataceae). Evolution, 57, 1973-1988. https://doi.org/10.1111/ j.0014-3820.2003.tb00378.x

Dorken, M. E., \& Barrett, S. C. H. (2004a). Chloroplast haplotype variation among monoecious and dioecious populations of Sagittaria latifolia (Alismataceae) in eastern North America. Molecular Ecology, 13, 2699-2707. https://doi.org/10.1111/j.1365-294X.2004.02246.x

Dorken, M. E., \& Barrett, S. C. H. (2004b). Sex determination and the evolution of dioecy from monoecy in Sagittaria latifolia (Alismataceae). Proceedings of the Royal Society of London Series B: Biological Sciences, 271, 213-219. https://doi.org/10.1098/ rspb.2003.2580

Dorken, M. E., Friedman, J., \& Barrett, S. C. H. (2002). The evolution and maintenance of monoecy and dioecy in Sagittaria latifolia (Alismataceae). Evolution, 56, 31-41. https://doi.org/10.1111/ j.0014-3820.2002.tb00847.x

Dorken, M. E., \& Van Drunen, W. E. (2010). Sex allocation in clonal plants: Might clonal expansion enhance fitness gains through male function? Evolutionary Ecology, 24, 1463-1474. https://doi.org/10.1007/s1068 2-010-9393-2

Eckert, C. G. (2000). Contributions of autogamy and geitonogamy to self-fertilization in a mass-flowering, clonal plant. Ecology, 81, 532542. https://doi.org/10.1890/0012-9658(2000)081[0532:COAAGT] 2.0.CO;2

Fox, J., \& Weisberg, S. (2011). An R companion to applied regression. Thousand Oaks, CA: Sage.
Handel, S. N. (1985). The intrusion of clonal growth patterns on plant breeding systems. The American Naturalist, 125, 367-384. https:// doi.org/10.1086/284348

Harder, L. D., \& Barrett, S. C. H. (1995). Mating cost of large floral displays in hermaphrodite plants. Nature, 373, 512-515. https://doi. org/10.1038/373512a0

Hardy, O. J., González-Martínez, S. C., Fréville, H., Boquien, G., Mignot, A., Colas, B., \& Olivieri, I. (2004). Fine-scale genetic structure and gene dispersal in Centaurea corymbosa (Asteraceae) I. Pattern of polIen dispersal. Journal of Evolutionary Biology, 17, 795-806. https://doi. org/10.1111/j.1420-9101.2004.00713.x

Holt, R., Kwok, A., \& Dorken, M. E. (2019). Increased spatial-genetic structure in a population of the clonal aquatic plant Sagittaria latifolia (Alismataceae) following disturbance. Heredity, 124(3), 514-523. https://doi.org/10.1038/s41437-019-0286-z

Jones, O., \& Wang, J. (2010). COLONY: A program for parentage and sibship inference from multilocus genotype data. Molecular Ecology Resources, 10, 551-555. https://doi.org/10.1111/j.17550998.2009.02787.x

Kalinowski, S. T., Taper, M. L., \& Marshall, T. C. (2007). Revising how the computer program CERVUS accommodates genotyping error increases success in paternity assignment. Molecular Ecology, 16, 1099-1106. https://doi.org/10.1111/j.1365-294X.2007.03089.x

Karron, J. D., \& Mitchell, R. J. (2012). Effects of floral display size on male and female reproductive success in Mimulus ringens. Annals of Botany, 109, 563-570. https://doi.org/10.1093/aob/mcr193

Liao, W.-J., \& Harder, L. D. (2014). Consequences of multiple inflorescences and clonality for pollinator behavior and plant mating. The American Naturalist, 184, 580-592. https://doi.org/10.1086/ 678117

Liao, W.-J., Hu, Y., Zhu, B.-R., Zhao, X.-Q., Zeng, Y.-F., \& Zhang, D.-Y. (2009). Female reproductive success decreases with display size in monkshood, Aconitum kusnezoffii (Ranunculaceae). Annals of Botany, 104, 1405-1412. https://doi.org/10.1093/aob/mcp237

Loh, R., Scarano, F. R., Alves-Ferreira, M., \& Salgueiro, F. (2015). Clonality strongly affects the spatial genetic structure of the nurse species Aechmea nudicaulis (L.) Griseb. (Bromeliaceae). Botanical Journal of the Linnean Society, 178, 329-341. https://doi.org/10.1111/boj.12277

Marshall, T., Slate, J., Kruuk, L., \& Pemberton, J. (1998). Statistical confidence for likelihood-based paternity inference in natural populations. Molecular Ecology, 7, 639-655. https://doi.org/10.1046/ j.1365-294x.1998.00374.x

Matsuo, A., Tomimatsu, H., Suzuki, J.-I., Saitoh, T., Shibata, S., Makita, A., \& Suyama, Y. (2014). Female and male fitness consequences of clonal growth in a dwarf bamboo population with a high degree of clonal intermingling. Annals of Botany, 114, 1035-1041. https://doi. org/10.1093/aob/mcu176

Mizuki, I., Ishida, K., Tani, N., \& Tsumura, Y. (2010). Fine-scale spatial structure of genets and sexes in the dioecious plant Dioscorea japonica, which disperses by both bulbils and seeds. Evolutionary Ecology, 24, 1399-1415. https://doi.org/10.1007/s10682-010-9396-z

Perry, L. E., \& Dorken, M. E. (2011). The evolution of males: Support for predictions from sex allocation theory using mating arrays of Sagittaria latifolia (Alismataceae). Evolution, 65, 2782-2791. https:// doi.org/10.1111/j.1558-5646.2011.01344.x

Pieper, S. (2018). Hybridization dynamics in cattails (Typha spp.), in northeastern North America: Niche segregation, pollen dispersal, mating patterns, and the importance of local-scale processes (PhD thesis). Trent University, Canada.

R Core Team. (2018). R: A language and environment for statistical computing. Vienna, Austria: R Foundation for Statistical Computing.

Reusch, T. B. H. (2001). Fitness-consequences of geitonogamous selfing in a clonal marine angiosperm (Zostera marina). Journal of Evolutionary Biology, 14, 129-138. https://doi.org/10.1046/j.14209101.2001.00257.x 
Ritland, K. (2002). Extensions of models for the estimation of mating systems using $\mathrm{n}$ independent loci. Heredity, 88, 221. https://doi. org/10.1038/sj.hdy.6800029

Ruggiero, M. V., Reusch, T. B., \& Procaccini, G. (2005). Local genetic structure in a clonal dioecious angiosperm. Molecular Ecology, 14, 957-967. https://doi.org/10.1111/j.1365-294X.2005.02477.x

Schmitt, J. (1980). Pollinator foraging behavior and gene dispersal in Senecio (Compositae). Evolution, 34, 934-943. https://doi. org/10.1111/j.1558-5646.1980.tb04031.x

Schmitt, J. (1983). Density-dependent pollinator foraging, flowering phenology, and temporal pollen dispersal patterns in Linanthus bicolor. Evolution, 37, 1247-1257. https://doi.org/10.1111/j.1558-5646.1983. tb00241.x

Schnittler, M., \& Eusemann, P. (2010). Consequences of genotyping errors for estimation of clonality: A case study on Populus euphratica Oliv. (Salicaceae). Evolutionary Ecology, 24, 1417-1432. https://doi. org/10.1007/s10682-010-9389-y

Silander, J. A. (1985). Microevolution in clonal plants. In J. B. C. Jackson, L. W. Buss, \& R. E. Cook (Eds.), Population biology and evolution of clonal organisms (pp. 107-152). New Haven, CT: Yale University Press.

Somme, L., Mayer, C., Raspé, O., \& Jacquemart, A.-L. (2014). Influence of spatial distribution and size of clones on the realized outcrossing rate of the marsh cinquefoil (Comarum palustre). Annals of Botany, 113, 477-487. https://doi.org/10.1093/aob/mct280

Stephens, S., van Kleunen, M., \& Dorken, M. E. (2020). Data from: Patterns of pollen dispersal and mating in a population of the clonal plant Sagittaria latifolia. Dryad Digital Repository, https://doi. org/10.5061/dryad.qz612jmb8

Vallejo-Marín, M., Dorken, M. E., \& Barrett, S. C. H. (2010). The ecological and evolutionary consequences of clonality for plant mating. Annual Review of Ecology, Evolution, and Systematics, 41, 193-213. https://doi.org/10.1146/annurev.ecolsys.110308.120258

Van Drunen, W. E., \& Dorken, M. E. (2012). Trade-offs between clonal and sexual reproduction in Sagittaria latifolia (Alismataceae) scale up to affect the fitness of entire clones. New Phytologist, 196, 606-616. https://doi.org/10.1111/j.1469-8137.2012.04260.x

Van Drunen, W. E., van Kleunen, M., \& Dorken, M. E. (2015). Consequences of clonality for sexual fitness: Clonal expansion enhances fitness under spatially restricted dispersal. Proceedings of the National Academy of Sciences of the United States of America, 112, 8929-8936. https://doi.org/10.1073/pnas.1501720112

van Kleunen, M., Pyšek, P., Dawson, W., Essl, F., Kreft, H., Pergl, J., ... Lenzner, B. (2019). The Global Naturalized Alien Flora (GloNAF) database. Ecology, 100, e02542.

Van Rossum, F., Stiers, I., Van Geert, A., Triest, L., \& Hardy, O. J. (2011). Fluorescent dye particles as pollen analogues for measuring pollen dispersal in an insect-pollinated forest herb. Oecologia, 165(3), 663-674. https://doi.org/10.1007/s00442-010-1745-7

Vandepitte, K., De Meyer, T., Jacquemyn, H., Roldan-Ruiz, I., \& Honnay, O. (2013). The impact of extensive clonal growth on fine-scale mating patterns: A full paternity analysis of a lily-of-the-valley population (Convallaria majalis). Annals of Botany, 111, 623-628. https://doi. org/10.1093/aob/mct024

Wang, J. (2004). Sibship reconstruction from genetic data with typing errors. Genetics, 166, 1963-1979. https://doi.org/10.1534/genetics. 166.4.1963

Wang, J. (2018). Estimating genotyping errors from genotype and reconstructed pedigree data. Methods in Ecology and Evolution, 9, 109-120. https://doi.org/10.1111/2041-210X.12859

Wang, X., Zhou, W., Lu, J., Wang, H., Xiao, C., Xia, J., \& Liu, G. (2012). Effects of population size on synchronous display of female and male flowers and reproductive output in two monoecious Sagittaria species. PLoS ONE, 7, e48731. https://doi.org/10.1371/journal. pone.0048731

Weiner, J., Campbell, L. G., Pino, J., \& Echarte, L. (2009). The allometry of reproduction within plant populations. Journal of Ecology, 97, 12201233. https://doi.org/10.1111/j.1365-2745.2009.01559.x

Wilson, P., Thomson, J. D., Stanton, M. L., \& Rigney, L. P. (1994). Beyond floral Batemania: Gender biases in selection for pollination success. The American Naturalist, 143(2), 283-296. https://doi. org/10.1086/285604

Yakimowski, S. B., \& Barrett, S. C. H. (2014). Clonal genetic structure and diversity in populations of an aquatic plant with combined vs. separate sexes. Molecular Ecology, 23, 2914-2928. https://doi. org/10.1111/mec.12791

Yakimowski, S. B., Rymer, P. D., Stone, H., Barrett, S. C. H., \& Dorken, M. E. (2009). Isolation and characterization of 11 microsatellite markers from Sagittaria latifolia (Alismataceae). Molecular Ecology Resources, 9, 579-581. https://doi.org/10.1111/j.1755-0998.2008.02400.x 